Article

\title{
Three Types of Red Beetroot and Sour Cherry Based Marmalades with Enhanced Functional Properties
}

\author{
Oana Viorela Nistor ${ }^{1}$, Liliana Șeremet $(C e c l u)^{2}$, Gabriel Dănuț Mocanu ${ }^{1}\left(\mathbb{D}\right.$, Vasilica Barbu ${ }^{1}{ }^{(\mathbb{D}}$, \\ Doina Georgeta Andronoiu ${ }^{1}$ and Nicoleta Stănciuc ${ }^{1, *}$ \\ 1 Faculty of Food Science and Engineering, Dunărea de Jos University of Galati, 800201 Galati, Romania; \\ Oana.Nistor@ugal.ro (O.V.N.); Danut.Mocanu@ugal.ro (G.D.M.); Vasilica.Barbu@ugal.ro (V.B.); \\ Georgeta.Andronoiu@ugal.ro (D.G.A.) \\ 2 Faculty of Economics, Engineering and Applied Sciences Cahul State University "B.P. Hasdeu", \\ 3901 Cahul, Moldova; ceclu.liliana@gmail.com \\ * Correspondence: Nicoleta.Stanciuc@ugal.ro; Tel.: +40-0336-130-183
}

Academic Editor: Angela Cardinali

Received: 11 October 2020; Accepted: 30 October 2020; Published: 2 November 2020

\begin{abstract}
The importance of bioactive compounds such as betalains and anthocyanins was highlighted in the present study by the valorization of red beetroot and sour cherry as an attempt to develop healthy products. The aim of the study was to obtain and characterize three types of marmalade based on red beetroot, sour cherry and both in $1: 1$ combination, obtained by heating at $95^{\circ} \mathrm{C}$ for $30 \mathrm{~min}$. Changes in total phenolic content, total flavonoids, betalains, anthocyanins and antioxidant activity were evaluated before and after the thermal treatment. Several other analyses such as color, rheological and textural analyses and confocal laser microscopy were performed to provide further information about the quality of the added-value food products. A significant decrease of $34 \%$ in betalains content was registered in the red beetroot marmalade due to the chemical changes in bioactives induced by the temperature. A satisfactory ABTS radical scavenging activity of $8.12 \pm 0.38 \mathrm{mMol}$ Trolox $/ \mathrm{g}$ dry weight $(\mathrm{dw})$ was obtained for the red beetroot and sour cherry based marmalade. The gelled structure was validated by the rheological and textural characteristics. The results highlighted the potential use of red beetroot and sour cherry as food raw materials, due to their particular profile of bioactive compounds.
\end{abstract}

Keywords: red beetroot; sour cherry; marmalade; bioactive compounds; antioxidant activity

\section{Introduction}

Fresh fruit and vegetable consumption is increasingly recognized for significant nutritional and functional added-values in the human diet. In the last decades, increased attention has been given to red beetroot due to its nutritional and biological properties. However, due to its specific smell and taste, not all consumers find it pleasant and tasty. Therefore, red beetroot is often combined in the diet with various fruits and vegetables such as carrots, tomatoes, apples, sweet cherries or sour cherries. Red beetroots are consumed in raw form, sometimes shredded as a salad; consumed after thermal processing in which they are grilled, boiled, steamed, roasted, sautéed, canned or even transformed into chips [1]; or introduced as powders into different fortified products.

Beetroot (Beta vulgaris L.) originated in Asia and Europe, belonging to the family of Chenopodiaceae [2]. The beetroot is known for its high concentration of bioactive compounds such as betalains, polyphenols, carotenoids and flavonoids, thus providing significant nutritional and health benefits [3]. Probably the most studied bioactive compounds in beetroot, the betalains are classified as betacyanins (responsible for red pigmentation) and betaxanthins (related to yellow color). These are water-soluble nitrogen-containing pigments, found in high concentrations in red 
beetroot, with reported antimicrobial and antiviral effects [4], potential to inhibit cell proliferation in human tumor cells [5], inhibitory activity towards cervical ovarian and bladder cancer cells in vitro [6], anti-inflammatory effects and antiradical and antioxidant activity [7]. Additionally, red beetroot contains high amounts of vitamins, such as vitamins B, C, A and $K$, and minerals [8,9].

Bioactive compounds, such as betalains and polyphenols, are widely found in nature, namely in fruits and vegetables. Several epidemiological studies reported that these compounds have the ability to exert biological effects and play a crucial role in preventing diseases linked to oxidative stress. These natural components with antioxidant and antimicrobial properties present great potential in food preservation, gaining relevance in the field of food science and food engineering [10,11]. Red beet and sour cherry are among the most popular natural sources of bioactives owing to not only their nutrient-dense properties, containing betalains and polyphenols, especially anthocyanins, but also their intense aromatic flavor.

The natural pigments from red beetroot are already commercially available as red food colorant recognized by the European Union and Food and Drug Administration (FDA) [12], with multiple uses in nondairy drinks [13], noodles [3], gummy candies, beverages and processed meat products [14].

Sour cherry (Prunus cerasus L.), known as tart cherry, is a fruit of the Rosaceae family and is native to northeastern Anatolia [15]. The fruits have a characteristic sour taste and dark red color and are rich in anthocyanins, phenolic acids and flavonoids, such as cyanidin-3-rutinoside, peonidin-3-glucoside, isorhamnetin, quercetin, ferulic acid, chlorogenic acid and $p$-coumaric acid [16]. Due to its rich composition in bioactives, sour cherry is recognized for functional properties in preventing various diseases (preventing neurological diseases, diabetes, obesity and cardiovascular and inflammatory diseases by strong antioxidant, antidiabetic, antiobesity, antimutagenic and anticarcinogenic properties) [17].

Therefore, the aim of this study was to obtain and to characterize a new functional product, namely marmalade, based on red beetroot, sour cherry fruit and agar-agar, with no added sugar. Three different technological variants were analyzed in terms of betalains content, polyphenols, flavonoids, antioxidant activity, color and rheological and textural characteristics. The structure and morphological particularities of the samples were analyzed by confocal electron microscopy. The results highlight the potential use of red beetroot and sour cherry as food raw materials, providing multifunctional properties, due to their particular profile of bioactive compounds.

\section{Results}

\subsection{The Analysis of Phytochemicals in Fresh, Unprocessed Samples}

The phytochemical profiles, in terms of betalains, total monomeric anthocyanins, total polyphenols, flavonoids and antioxidant activity were analyzed by spectrophotometric methods in fresh samples, before thermal processing. The total betalains content in fresh red beetroot samples was $8.35 \pm 0.31 \mathrm{mg} / \mathrm{g}$ dry weight $(\mathrm{dw})$, which is comparable with the results reported by Castellanos-Santiago and Yahia [18] for red beetroot and Mexican prickly pear, whereas the total polyphenol content (TPC) and total flavonoid content (TFC) were $18.33 \pm 0.72 \mathrm{mg}$ gallic acid equivalents (GAE) $/ \mathrm{g} \mathrm{dw}$ and $13.19 \pm 0.28 \mathrm{mg}$ quercetin equivalents $(\mathrm{QE}) / \mathrm{g} d \mathrm{w}$, respectively. Desseva et al. [19] reported values for TPC and TFC of $30.81 \pm 2.96 \mathrm{mg} \mathrm{GAE} / \mathrm{g} \mathrm{dw}$ and $6.72 \pm 0.16 \mu \mathrm{g}$ quercetin equivalents/g dw, respectively, in red beetroot juice.

As expected, the fresh sour cherry sample showed a significant content of monomeric anthocyanins $(0.64 \pm 0.01 \mathrm{mg}$ cyanidin glucoside equivalents-CGE/g dw), whereas TPC (30.17 $\pm 0.12 \mathrm{mg} \mathrm{GAE} / \mathrm{g} \mathrm{dw})$ and TFC (21.4 $\pm 0.04 \mathrm{mg} \mathrm{QE} / \mathrm{g} \mathrm{dw})$ showed values that were significantly higher $(p>0.05)$ when compared with red beetroot samples. However, no significant differences $(p<0.05)$ were found in antioxidant activities of the fresh samples, thus supporting the hypothesis that anthocyanins and betalains are the main compounds responsible for antioxidant activity of fresh sour cherry and red beetroot samples. When combining red beetroot and sour cherry in a ratio of 1:1, the phytochemical 
profile revealed an anthocyanin content of $0.61 \pm 0.03 \mathrm{mg} \mathrm{CGE} / \mathrm{g} \mathrm{dw}$. Table 1 shows the physical and phytochemical results of the tested fresh and marmalade samples.

\subsection{Phytochemical Profile of the Heat Treated Samples}

After processing, the marmalade variants were coded, with B representing the red beetroot marmalade, $\mathrm{S}$ representing the sour cherry marmalade and BS representing the combination of red beetroot and sour cherry marmalade. The heated samples were treated at $95^{\circ} \mathrm{C}$ for $30 \mathrm{~min}$ in order to assure the main characteristics and the specific conservation of marmalade. As for the fresh samples, the phytochemicals profiles were analyzed after the thermal processing. Thus, when compared to the fresh samples, the red beetroot marmalade (B) registered a significant decrease of $34 \%$ in total betalains content, from $4.34 \pm 0.18 \mathrm{mg} / \mathrm{g} \mathrm{dw}$ to $3.10 \pm 0.08 \mathrm{mg} / \mathrm{g} \mathrm{dw}$ betacyanin and from $4.01 \pm 0.03$ to $2.43 \pm 0.07 \mathrm{mg} / \mathrm{g} \mathrm{dw}$ betaxanthin. The lower betalains concentration for the processed samples could be due to the isomerization, decarboxylation and/or cleavage of betacyanins during processing [20]. Betacyanins seems to be more heat-stable, with a decrease oapproximately $29 \%$, whereas betaxanthins decreased by more than 39\%. Ravichandran et al. [21] showed similar levels of betacyanin and betaxanthin decrease $(6 \%-33 \%)$ after the heating of red beetroot at $80{ }^{\circ} \mathrm{C}$ for 60,120 and $180 \mathrm{~s}$. Significant decreases of approximately $60 \%$ and $63 \%$ were observed in TFC and TPC, respectively.

The monomeric anthocyanins of the sour cherry sample (S) decreased by $28 \%$ in the processed samples compared to the fresh ones, whereas TPC and TFC showed decreases of $25 \%$ and $49 \%$, respectively, suggesting a stronger thermoprotective effect of the sour cherry matrix.

From Table 1, it can be observed that the food matrix obtained from the combination of red beetroot and sour cherry showed a more protective effect on bioactives, with decreases in TPC and TFC of $35 \%$ and $30 \%$, respectively, whereas the anthocyanin concentration was by approximately $50 \%$. Betalains seemed to be more stable, with betacyanin and betaxanthin concentrations of $0.83 \pm 0.024$ and $1.04 \pm 0.03 \mathrm{mg} / \mathrm{g} \mathrm{dw}$, respectively, in the processed food.

The most important reduction in antioxidant activity was found for red beetroot and was correlated with the decrease in TPC and TFC. Good preservation of ABTS radical scavenging activity was observed for the processed sour cherry marmalade, with a decrease of approximately $36 \%$ during thermal processing. An explanation could be related to the possible presence of polyhydroxylated and polymethoxylated glycosides [22], which are produced by the anthocyanin polymerization processes as an effect of the thermal treatment [23]. The newly made marmalade product, obtained by combining sour cherry and red beetroot (BS), showed a satisfactory ABTS radical scavenging activity of $8.12 \pm 0.38 \mathrm{mMol}$ Trolox $/ \mathrm{g} \mathrm{dw}$. The antioxidant activity (determined by the DPPH method) varied between $0.87 \pm 0.07$ and $2.75 \pm 0.02 \mu \mathrm{Mol}$ Trolox/g dw for the marmalade samples, with the lowest values being measured in the B sample. Similar to the results obtained by ABTS assay, the antioxidant activity was influenced by the thermal treatment (Table 1 ). 
Table 1. Physical and phytochemical results of the tested fresh and marmalade samples.

\begin{tabular}{|c|c|c|c|c|c|c|c|c|}
\hline \multirow[b]{2}{*}{ Code } & \multirow[b]{2}{*}{$\mathbf{a}_{\mathbf{w}}$} & \multirow{2}{*}{$\begin{array}{c}\text { TPC, } \\
\text { mg GAE/g dw }\end{array}$} & \multirow{2}{*}{$\begin{array}{c}\text { TFC, } \\
\mathrm{mg} \mathrm{QE} / \mathrm{g} \mathrm{dw}\end{array}$} & \multirow{2}{*}{$\begin{array}{c}\text { ABTS Radical } \\
\text { Scavenging Activity, } \\
\text { mMol Trolox/g dw }\end{array}$} & \multirow{2}{*}{$\begin{array}{c}\text { DPPH, } \mu \mathrm{M} \\
\text { Trolox/g dw }\end{array}$} & \multicolumn{2}{|c|}{ Betalains } & \multirow{2}{*}{$\begin{array}{c}\text { TAC, } \\
\mathrm{mg} \mathrm{C} 3 \mathrm{G} / \mathrm{g} d w\end{array}$} \\
\hline & & & & & & $\begin{array}{c}\beta-C y a n i n \\
\mathrm{mg} / \mathrm{g} \mathrm{dw}\end{array}$ & $\begin{array}{c}\beta \text {-Xanthin, } \\
\mathrm{mg} / \mathrm{g} \mathrm{dw}\end{array}$ & \\
\hline $\mathrm{B}_{0}$ & $0.94 \pm 0.02^{\mathrm{a}}$ & $18.33 \pm 0.72^{\mathrm{a}}$ & $13.19 \pm 0.28^{b}$ & $13.10 \pm 2.31^{a}$ & $1.80 \pm 0.04^{\mathrm{a}}$ & $4.34 \pm 0.18^{a}$ & $4.01 \pm 0.03^{a}$ & - \\
\hline B & $0.86 \pm 0.01^{b}$ & $6.88 \pm 0.22^{b}$ & $5.33 \pm 0.08^{c}$ & $3.88 \pm 0.57^{c}$ & $0.87 \pm 0.07^{c}$ & $3.10 \pm 0.08^{b}$ & $2.43 \pm 0.07^{b}$ & - \\
\hline $\mathrm{S}_{0}$ & $0.98 \pm 0.01^{\mathrm{a}}$ & $30.17 \pm 0.12^{a}$ & $21.4 \pm 0.04^{b}$ & $17.77 \pm 0.16^{\mathrm{a}}$ & $4.30 \pm 0.05^{\mathrm{a}}$ & - & - & $0.64 \pm 0.01^{\mathrm{a}}$ \\
\hline S & $0.86 \pm 0.02^{b}$ & $22.78 \pm 1.19^{b}$ & $10.93 \pm 0.51^{c}$ & $11.38 \pm 0.42^{c}$ & $2.75 \pm 0.02^{c}$ & - & - & $0.46 \pm 0.08^{b}$ \\
\hline $\mathrm{BS}_{0}$ & $0.96 \pm 0.01^{\mathrm{a}}$ & $20.12 \pm 0.42^{a}$ & $13.86 \pm 0.16^{b}$ & $14.22 \pm 0.13^{a}$ & $2.53 \pm 0.03^{a}$ & $1.27 \pm 0.03^{\mathrm{a}}$ & $1.38 \pm 0.02^{\mathrm{a}}$ & $0.61 \pm 0.03^{a}$ \\
\hline BS & $0.83 \pm 0.01^{b}$ & $13.01 \pm 0.39^{b}$ & $9.83 \pm 0.45^{c}$ & $8.12 \pm 0.38^{c}$ & $1.44 \pm 0.04^{c}$ & $0.83 \pm 0.024^{b}$ & $1.04 \pm 0.03^{b}$ & $0.31 \pm 0.09^{b}$ \\
\hline
\end{tabular}

$\mathrm{a}_{\mathrm{w}}$, water activity; TPC, total phenolic content; TFC, total flavonoid content; TAC, total anthocyanin content; $\mathrm{B}_{0}$, fresh red beetroot; $\mathrm{S}_{0}$, fresh sour cherry; $\mathrm{BS}_{0}$, fresh red beetroot and sour cherry; B, red beetroot marmalade; $S$, sour cherry marmalade; BS, red beetroot and sour cherry marmalade. Values are represented as mean \pm standard errors. Different superscript letters $(a, b, c)$ mean a significant difference at $(p<0.05)$ among different parameters for the same column. 


\subsection{Water Activity $\left(a_{w}\right)$ of the Samples}

It is well known that long-term storage stability is achieved through a combination of the equilibrium between thermal processing and control of water activity. After the composition, boiling is the most important process in marmalade making. Thus, the samples were processed by using a Multicooker. Due to the hermetic seal of the equipment, an increase in vapor pressure can be achieved, ensuring that the product is not affected by the caramelization process.

The values obtained for the water activity of the marmalade samples were in the range of 0.83 to 0.86 (Table 1). These values are important for canned foods, considering that the minimum $\mathrm{a}_{\mathrm{w}}$ level for the growth of Clostridium botulinum is approximately 0.93 .

\subsection{Color Measurement}

Colors are important quality indicators that determine the consumer acceptance of foods. Table 2 shows the color parameters of the marmalade samples.

Table 2. Color parameters of marmalades.

\begin{tabular}{cccc}
\hline \multirow{2}{*}{ Color Parameters } & \multicolumn{3}{c}{ Marmalades } \\
\cline { 2 - 4 } & B & S & BS \\
\hline$L^{*}$ (clarity) & $21.50 \pm 0.28^{\mathrm{a}, *}$ & $29.66 \pm 0.02^{\mathrm{b}}$ & $25.32 \pm 0.05^{\mathrm{b}}$ \\
$a^{*}$ (red/green color component) & $15.02 \pm 0.21^{\mathrm{a}}$ & $18.41 \pm 0.17^{\mathrm{b}}$ & $22.46 \pm 0.08^{\mathrm{b}}$ \\
$b^{*}$ (blue/yellow color component) & $4.29 \pm 0.14^{\mathrm{a}}$ & $7.40 \pm 0.09^{\mathrm{b}}$ & $7.50 \pm 0.04^{\mathrm{b}}$ \\
$\Delta E$ (total color difference) & $7.01 \pm 0.23^{\mathrm{a}}$ & $6.46 \pm 0.10^{\mathrm{a}}$ & $5.48 \pm 0.05^{\mathrm{a}}$ \\
$C^{*}$ (chroma) & $15.62 \pm 0.12^{\mathrm{a}}$ & $19.84 \pm 0.19^{\mathrm{b}}$ & $23.67 \pm 0.09^{\mathrm{b}}$ \\
$h^{*}$ (hue angle) & $15.94 \pm 0.48^{\mathrm{a}}$ & $21.89 \pm 0.11^{\mathrm{b}}$ & $18.46 \pm 0.04^{\mathrm{a}}$ \\
\hline
\end{tabular}

Values are represented as mean \pm standard errors. Different superscript letters (a and $b$ ) mean a significant difference at $(p<0.05)$ among different parameters on the same row. ${ }^{*}$ Standard deviations values.

The values of the $L^{*}$ parameter ranged between $21.5 \pm 0.28$ and $29.66 \pm 0.02$. The processed products were darker compared to the fresh samples (lower $L^{*}$ values), probably due to non-enzymatic browning determined by sugar caramelization or Maillard reactions (data not shown). Similar results were obtained by Igual et al. [24] in the case of grapefruit jams. The processing procedure decreased $a^{*}$ value. The B marmalade was less reddish when compared with $S$ and BS samples due to the presence of anthocyanins. Anthocyanins are reported to have a significant role in the color quality of many fruits. The yellow-blue coordinates $\left(b^{*}\right)$ were higher for S and BS, ranging from $7.40 \pm 0.09$ (S) to $4.29 \pm 0.14$ (B). Throughout the processing period, the proportion of yellow color increased due to the temperature and cooking time when compared to the control samples. Rababah et al. [25] observed an increase in the $b^{*}$ parameter when examining cherry jams. The color of the marmalades revealed that the total color difference $(\Delta E)$ was higher in the case of the $S$ sample $(7.01 \pm 0.23)$. The major causes of color change were probably because of the browning reactions. Chroma $\left(C^{*}\right)$, the measure of color saturation, decreased in the case of processed samples, which indicates that the color of these samples is not so intense. The Chroma values of all the processed samples were between $15.62 \pm 0.12$ (B) and $23.67 \pm 0.09$ (BS). The hue angle $\left(h^{*}\right)$, which describes the color wheel/cycle, of all of the samples ranged from $15.94 \pm 0.48$ (B) to $21.89 \pm 0.11$ (S).

\subsection{Rheological Measurements Results}

Viscosity curves for the tested marmalades were generated by evaluating the strain from $0.01 \%$ to $100 \%$ using geometry with grooved surfaces to avoid apparent wall slip. When the structure of the samples is not affected during the test, $G$ ' and $G$ " relate to the "solid-like" and "liquid-like" properties of the samples, respectively [26].

The low amplitude oscillatory measurements revealed a good resistance of sour cherry marmalade to the applied strain, with $G^{\prime}-G^{\prime \prime}$ intersection point at $\sim 26 \%$ strain. This compensated for the poor 
rheological properties of B-flow point at 4\% strain and narrow LVR, for the marmalade obtained by mixing the two ingredients (BS). However, B presented the highest consistency, with $G^{\prime}$ values up to $7 \mathrm{kPa}$. $G^{\prime}$ registered greater values than $G^{\prime \prime}$ at any given point in the frequency sweep tests; this is typical behavior for gels with a predominantly elastic character. For all the marmalade samples, the slip effects occurred for both the smooth and grooved geometries. These may be due to the presence of the fibers, which are present in all samples, similar to the results obtained by Barbieri et al. [27] for the pulp and jam of gabiroba.

The dynamic viscoelastic properties of marmalades were evaluated by elastic $\left(G^{\prime}\right)$ and viscous $\left(G^{\prime \prime}\right)$ moduli as a function of frequency (Figure 1). Both moduli had a slight frequency dependence, with $G^{\prime}$ exceeding $G^{\prime \prime}$ at all the frequencies analyzed $(0.1-100 \mathrm{~Hz})$.
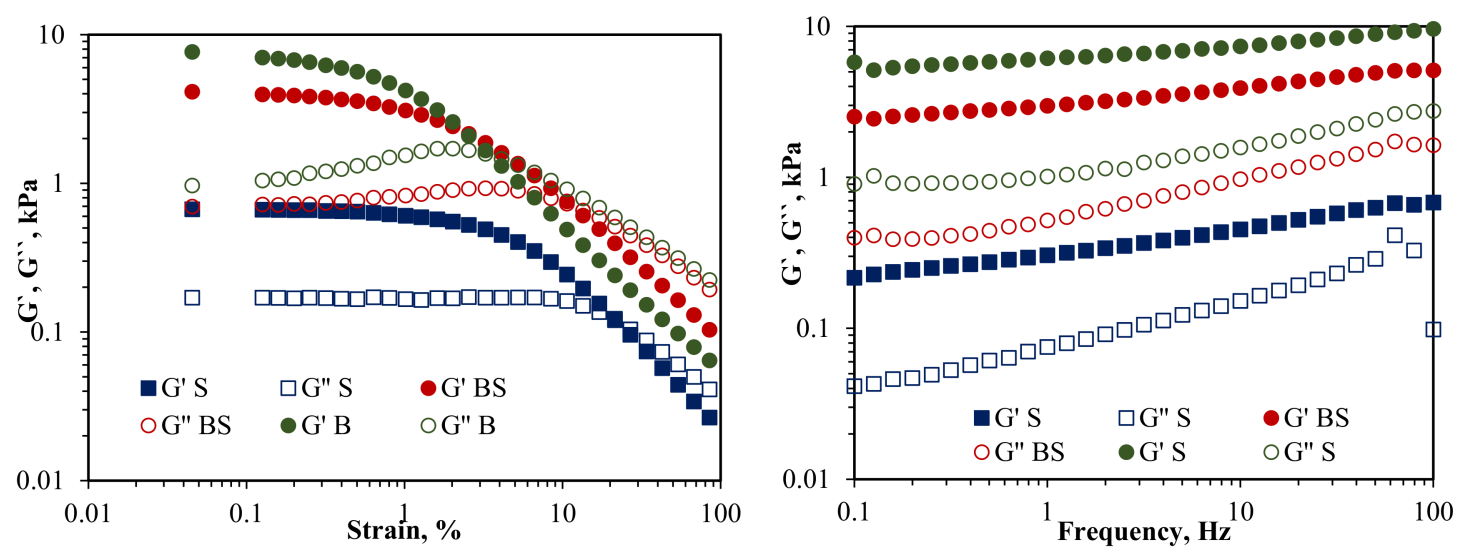

Figure 1. Elastic modulus $\left(\mathrm{G}^{\prime}\right)$ and viscous modulus $\left(\mathrm{G}^{\prime \prime}\right)$ variation with stain and frequency (B, red beetroot marmalade; $S$, sour cherry marmalade; BS, red beetroot and sour cherry marmalade).

The results are in accordance with those of Basu et al. [28] for mango jam and Gabriele et al. [29] for jam and yoghurt. Considering these results, the $G^{\prime}$ and $G^{\prime \prime}$ values of each marmalade sample were averaged and represented as a function of the angular frequency. It seems that the $G^{\prime}$ of all samples increased with the frequency, which indicates a relaxation process of the marmalade matrix. However, the values of $G^{\prime}$ and $G^{\prime \prime}$ seem to be not parallel, so the samples are considered strong gels, in contradiction with the findings of Figueroa et al. [30] for fruit jellies enriched with dietary fiber. All three samples presented a low frequency dependence with no $G^{\prime}-G^{\prime \prime}$ intersection point over the entire tested frequency range.

\subsection{Texture Analysis Results}

Table 3 shows that all the values of all textural parameters for the BS sample are between the values of the other two samples.

Table 3. Values of marmalade textural parameters.

\begin{tabular}{cccc}
\hline \multirow{2}{*}{ Texture Parameter } & \multicolumn{3}{c}{ Sample } \\
\cline { 2 - 4 } & B & S & BS \\
\hline Firmness, N & $2.99 \pm 0.07^{\mathrm{a}, *}$ & $1.53 \pm 0.08^{\mathrm{b}}$ & $2.09 \pm 0.07^{\mathrm{b}}$ \\
Adhesiveness, $\mathrm{mJ}$ & $5.26 \pm 0.88^{\mathrm{a}}$ & $1.18 \pm 0.03^{\mathrm{b}}$ & $4.73 \pm 0.17^{\mathrm{a}}$ \\
Cohesiveness, - & $0.32 \pm 0.01^{\mathrm{b}}$ & $0.65 \pm 0.05^{\mathrm{b}}$ & $0.36 \pm 0.01^{\mathrm{b}}$ \\
Springiness, $\mathrm{mm}$ & $6.67 \pm 0.62^{\mathrm{a}}$ & $8.85 \pm 0.57^{\mathrm{a}}$ & $7.53 \pm 0.52^{\mathrm{a}}$ \\
\hline
\end{tabular}

* Standard deviations; B, red beetroot marmalade; S, sour cherry marmalade; BS, the combination of red beetroot and sour cherry marmalade. Values are represented as mean \pm standard errors. Different superscript letters $(a$ and $b$ ) mean a significant difference at $(p<0.05)$ among different parameters on the same row. 
From Table 3 it can be seen that the highest firmness $(2.99 \mathrm{~N})$ was registered for beetroot marmalade, while the lowest firmness $(1.53 \mathrm{~N})$ was registered for sour cherry marmalade. The combined marmalade had an intermediate value of $2.09 \mathrm{~N}$. This behavior is due to the vegetal material microstructure: the fibrous tissue fragments from beetroot determine a high resistance to penetration. Similar firmness values were reported by Banas et al. [31] for low-sugar gooseberry jams enriched with plant ingredients and by Garrido et al. [32] for apple jellies.

Adhesiveness is a measure of the work required to withdraw the probe from the sample. In our study, these parameters registered values between $1.17 \mathrm{~mJ}$ for the $\mathrm{S}$ sample and $5.26 \mathrm{~mJ}$ for the B sample. The most cohesive sample was the $S$ sample. The mixing of red beetroot with sour cherries resulted in weakening the bonds between the structural elements of the sample. A similar effect was noticed for springiness.

\subsection{Structural Particularities of the Marmalades}

The confocal scanning microscopy revealed the presence of selected biologically active compounds, such as betalains (Bt) in red beetroot marmalade and anthocyanins (An) in sour cherry marmalade (Figure 2).

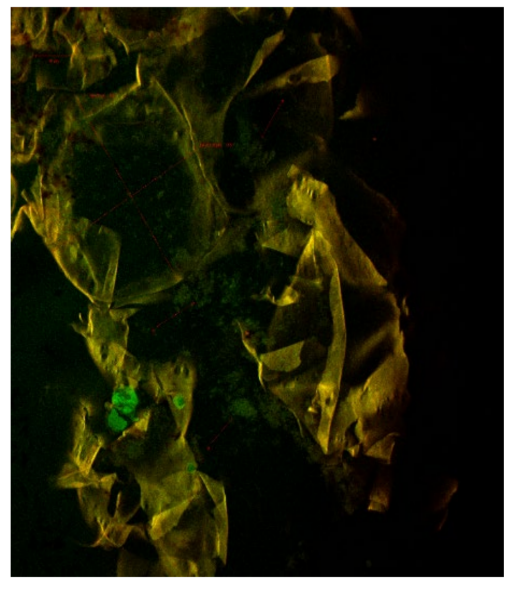

(a)

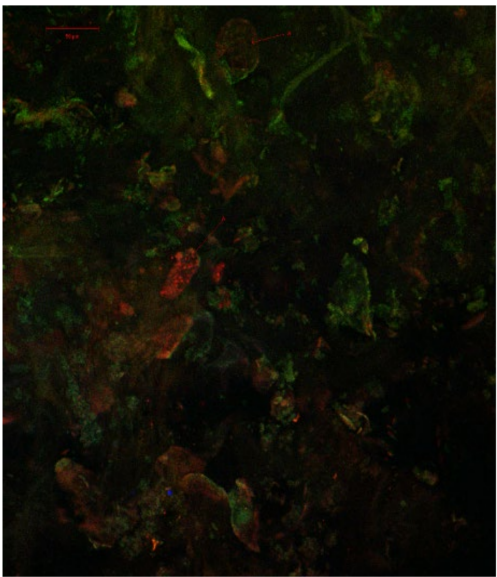

(b)

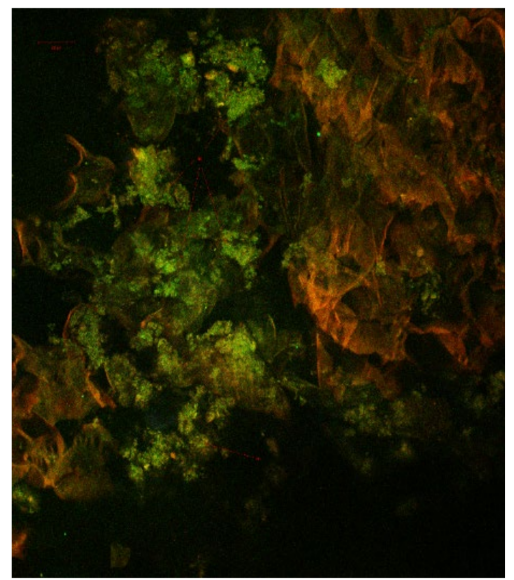

(c)

Figure 2. The confocal laser scanning microscopy images for the marmalade samples: (a) red beetroot, (b) red beetroot and sour cherry and (c) sour cherry.

Similar results are reported by Miguel [33] and Cabrera-Bañegil et al. [34]. The compounds were aggregated in clusters of variable sizes, which could be due to the agar-agar addition. The structural and biochemical characteristics of both vegetal tissues could explain the differences in cellular wall behavior in response to the same thermal treatment. The cells from the sour cherry marmalade were completely lysed, more than those of red beetroot. The marmalade made from or with red beetroot contained more or less undamaged tissue fragments belonging to the root parenchyma with cells of 233.03-269.49 $\mu \mathrm{m}$.

\section{Materials and Methods}

\subsection{Chemicals}

Agar-agar (Biovegan, Bonefeld, Germany), ethanol, Folin-Ciocalteu's reagent, sodium carbonate, ABTS (2,2-azino-bis(3-ethylbenzothiazoline-6-sulfonic acid) diammonium salt), quercetin, methanol, aluminum chloride, potassium chloride, sodium acetate and $\mathrm{HCl}$ were purchased from Sigma Aldrich (MilliporeSigma, Steinheim, Germany). 


\subsection{Plant Material}

Fresh red beetroot (Beta vulgaris L.) and frozen sour cherries (Prunus cerasus L.) were purchased from a local market (Carrefour) from Galati, Romania between February and March 2020. Fresh red beetroot was washed, peeled, cut into cubes and stored at $-20^{\circ} \mathrm{C}$.

\subsection{Marmalade Making}

Three variants of marmalade were obtained based on frozen red beetroot, sour cherry and a combination of both of them in a ratio of 1:1. Frozen samples were mixed with $30 \%$ distilled water and 1\% agar-agar (Biovegan, Germany). The mixture was blended for $10 \mathrm{~min}$ at $1000 \mathrm{rpm}$ with a Philips HR2100/40 blender, EC (European Community). The mixture was heated in a Multicooker (Philips HD3037/70, $980 \mathrm{~W}, 5 \mathrm{~L}$, Eindhoven, the Netherlands) at a special program for jam manufacturing $\left(95^{\circ} \mathrm{C}\right.$ for $30 \mathrm{~min}$ ). The marmalades were processed until the dry weight was doubled. The marmalades were packed in jars and equilibrated at room temperature $\left(22^{\circ} \mathrm{C}\right)$ and then stored at $4{ }^{\circ} \mathrm{C}$ for 1 week before analysis. The variants were coded as follows: $\mathrm{B}$, the red beetroot marmalade; $\mathrm{S}$, the sour cherry marmalade; BS, the combination of red beetroot and sour cherry marmalade.

\subsection{Analysis of Betalains}

The betalain content was analyzed as described by Ravichandran et al. [20]. One gram of sample was dissolved in $10 \mathrm{~mL}$ of $20 \%$ ethanol and mixed for $10 \mathrm{~s}$, and then the homogenate was centrifuged at $6000 \times \mathrm{g}$ for $10 \mathrm{~min}$. The centrifugation was repeated 2 times to ensure maximum extraction of betalains. The supernatant was used for the determination of betalains. The content of betaxanthins and betacyanins in the extracts was determined spectrophotometrically at 538 and $480 \mathrm{~nm}$ with a UV-Vis spectrometer [35]. The betalain content (BC) was calculated according to Equation (1):

$$
B C=A \cdot D_{f} \cdot M_{W} \cdot \frac{V_{d}}{\varepsilon} \cdot L \cdot W_{d}, m g / g
$$

where $A$ is the absorbance, $D_{f}$ is the dilution factor, $V_{d}$ is the solution volume in milliliters, $W_{d}$ is the sample weight in grams and $L$ is the path length $(1 \mathrm{~cm})$ of the cuvette. For quantification of betacyanins the molecular weight $\left(M_{W}\right)$ and molar extinction coefficient $(\varepsilon)$ of $M_{W}=550 \mathrm{~g} / \mathrm{mol}$ and $\varepsilon=60,000 \mathrm{~L} /(\mathrm{mol} \mathrm{cm})$ were applied; for betaxanthins, these values were $M_{W}=308 \mathrm{~g} / \mathrm{mol}$ and $\varepsilon=48,000 \mathrm{~L} /(\mathrm{mol} \mathrm{cm})$.

\subsection{Total Anthocyanin Content}

A volume of $3 \mathrm{~mL}$ of extract was diluted in $5 \mathrm{~mL}$ of two different buffers: $0.025 \mathrm{M}$ potassium chloride, $\mathrm{pH}=1.0$, and $0.4 \mathrm{M}$ sodium acetate, $\mathrm{pH}=4.5$. After $30 \mathrm{~min}$ of incubation at room temperature, absorption (A) was measured at $\lambda=510$ and $700 \mathrm{~nm}$. All extracts were analyzed in triplicate. For calculation of total anthocyanins as cyanidin glucoside equivalents-CGE, the molar absorptivity coefficient $(\varepsilon)$ values $26,900 \mathrm{M}^{-1} \mathrm{~cm}^{-1}$ and the molecular weight of $449 \mathrm{Da}$ were used [36].

The results were calculated similarly to [37] as follows:

$$
\text { Asp }=(\text { A510 }- \text { A700) } \mathrm{pH} 1.0-(\mathrm{A} 510-\mathrm{A} 700) \mathrm{pH} 4.5
$$

The content of total anthocyanins (TA) were calculated as follows:

$$
\mathrm{TA}=\left(\mathrm{Asp} \times \mathrm{M} \times D_{f} \times 1000\right) /(\varepsilon \times \lambda \times \mathrm{m})
$$

where $D_{f}$ is the dilution factor, $\lambda$ is the cuvette optical path length $(1 \mathrm{~cm})$ and $\mathrm{m}$ is the weight of the sample in grams. The total anthocyanin content was expressed as $\mathrm{mg}$ CGE/g $\mathrm{dw}$. 


\subsection{ABTS Radical Scavenging Assay}

The fresh ABTS (2,2-azino-bis(3-ethylbenzothiazoline-6-sulfonic acid) diammonium salt) solution was diluted with ethanol (96\%) until the absorbance of $0.700 \pm 0.02$ at $734 \mathrm{~nm}$. Then, $10 \mu \mathrm{L}$ of the extract was added to $1 \mathrm{~mL}$ of the ABTS radical solution and shaken for $10 \mathrm{~s}$. One minute after the addition of the sample, the decolorization that was caused by the reduction of the cations by the antioxidants from the sample was measured spectrophotometrically at $734 \mathrm{~nm}$ (Biochrom Libra S22 UV/Vis, Cambridge, United Kingdom). The experiments were performed in triplicate. A standard curve using Trolox was used to express the antioxidant activity as $\mathrm{mMol}$ Trolox equivalent/g $\mathrm{dw}$. The experiments were performed in triplicate.

\subsection{DPPH Radical Scavenging Assay}

The antioxidant activity of the samples was determined as a measurement of radical scavenging using the DPPH radical. Thus, $100 \mu \mathrm{L}$ of a marmalade aqueous extract sample was mixed in triplicate with $3.0 \mathrm{~mL}$ of a DPPH work solution in absolute methanol. The mixture was incubated for $120 \mathrm{~min}$ in the dark at room temperature. The absorbance was measured at $515 \mathrm{~nm}$ against absolute methanol. For the control sample, the $100 \mu \mathrm{L}$ of marmalade aqueous extract was replaced with $100 \mu \mathrm{L}$ of absolute methanol. The results of the assay were expressed as Trolox equivalents (mM Trolox/g dw). The experiments were performed in triplicate.

\subsection{Water Activity}

The water activity of the samples was measured with a LabSwift water activity instrument (Novasina, Lachen, Switzerland). The experiments were performed in triplicate.

\subsection{Total Polyphenol Content (TPC)}

Five hundred microliters of the extract from each sample was introduced into test tubes and mixed with $2.5 \mathrm{~mL}$ of a tenfold dilute Folin-Ciocalteu reagent and $2 \mathrm{~mL}$ of $7.5 \%$ sodium carbonate. The tubes were covered with aluminum foil and allowed to stand for $30 \mathrm{~min}$ at room temperature before the absorbance was read at $765 \mathrm{~nm}$ using a UV-Vis spectrophotometer (Biochrom Libra S22 UV/Vis, Cambridge, United Kingdom) [38]. Each assay was performed in triplicate. The results were expressed as milligrams of gallic acid equivalents per gram dry weight (mg GAE/g dw).

\subsection{Total Flavonoid Content (TFC)}

The aluminum chloride colorimetric method was used for the determination of the total flavonoid content of the sample. For total flavonoid determination, quercetin was used to make the standard calibration curve. Stock quercetin solution was prepared by dissolving $5.0 \mathrm{mg}$ quercetin in $1.0 \mathrm{~mL}$ methanol, then the standard solutions of quercetin were prepared by serial dilutions using methanol $(5-200 \mu \mathrm{g} / \mathrm{mL})$. An amount of $0.6 \mathrm{~mL}$ diluted standard quercetin solutions or extracts was separately mixed with $0.6 \mathrm{~mL}$ of $2 \%$ aluminum chloride. After mixing, the solution was incubated for $60 \mathrm{~min}$ at room temperature. The absorbance of the reaction mixtures was measured against blank at $420 \mathrm{~nm}$ wavelength with a UV-Vis spectrophotometer (Biochrom Libra S22 UV/Vis, Cambridge, United Kingdom). The concentration of total flavonoid content in the test samples was calculated from the calibration plot and expressed as mg quercetin equivalent $(\mathrm{QE}) / \mathrm{g} d \mathrm{w}$ [39]. All the determinations were carried out in triplicate.

\subsection{Color Measurement}

The color was measured using a Minolta Chroma Meter CR-410 (Konica Minolta, Osaka, Japan) fitted with a granular accessory, after standardization with a white calibration plate according to the equipment specifications. The determined parameters were $L^{*}$ (lightness/darkness), $a^{*}$ (red/green) 
and $b^{*}$ (yellow/blue). The total color difference $(\Delta E)$ between samples was calculated according to Equation (3):

$$
\Delta E=\sqrt{\left(L_{0}^{*}-L^{*}\right)^{2}+\left(a_{0}^{*}-a^{*}\right)^{2}+\left(b_{0}^{*}-b^{*}\right)^{2}}
$$

Subscript 0 refers to the color of the fresh sample. The hue angle $\left(h^{*}\right)$, visual color appearance, chroma $\left(C^{*}\right)$ and color intensity were calculated according to Equations (4) and (5):

$$
\begin{aligned}
& C^{*}=\sqrt{a^{* 2}+b^{* 2}} \\
& h^{*}=\tan ^{-1}\left(\frac{b^{*}}{a^{*}}\right)
\end{aligned}
$$

Three replicates were carried out for each sample.

\subsection{Rheological Measurements}

The rheological behavior of marmalade samples was determined with a controlled stress rheometer AR2000ex (TA instruments Ltd., New Castle, DE, USA) equipped with a Peltier plate for temperature control and a plate geometry of $40 \mathrm{~mm}$ in diameter, with a set gap of $2 \mathrm{~mm}$. The system temperature was set to $20^{\circ} \mathrm{C}$. Low-amplitude dynamic shearing tests of strain sweep and frequency were applied, and storage modulus $\left(G^{\prime}\right)$ and loss modulus $\left(G^{\prime}\right)$ were registered. The strain sweep test was performed at an oscillatory frequency of $1 \mathrm{~Hz}$ while increasing strain from $0.01 \%$ to $100 \%$. It was used to identify the linear viscoelastic region (LVR) for all investigated samples. The dynamic frequency sweeps were further performed in the $0.1-100 \mathrm{~Hz}$ domain at a constant strain of $0.2 \%$ (determined to be within the linear viscoelastic region). The experiments were performed in triplicate.

\subsection{Texture Analysis}

The textural parameters (firmness, adhesiveness, cohesiveness and springiness) were determined with a Brookfield CT3 texture analyzer (AMETEK Brookfield, Middleboro, MA, USA). The samples were collected immediately after manufacturing and packed into cylindrical plastic containers, with $30 \mathrm{~mm}$ diameter and $50 \mathrm{~mm}$ height. The containers were kept at $4{ }^{\circ} \mathrm{C}$ for 1 week, and before testing they were equilibrated at room temperature for $3 \mathrm{~h}$. A double penetration test was applied, using a $25.4 \mathrm{~mm}$ acrylic cylinder. The testing parameters were set as follows: target distance $10 \mathrm{~mm}$, trigger load $0.067 \mathrm{~N}$, pretest speed $2 \mathrm{~mm} / \mathrm{s}$, test speed $1 \mathrm{~mm} / \mathrm{s}$, return speed $1 \mathrm{~mm} / \mathrm{s}$, load cell $1000 \mathrm{~g}$. The textural parameters were determined with TexturePro CT V1.5 software, provided by Brookfield Engineering Labs, Inc., AMETEK Brookfield, Middleboro, MA, USA. Five determinations for each sample were made and the presented results are the means of these determinations.

\subsection{Confocal Laser Scanning Microscopy (CLSM)}

The aim of the CLSM analyses was to highlight the size and morphology of the three variants of marmalade with red beetroot and sour cherry. For this study, a Zeiss LSM 710 confocal laser system (Carl Zeiss MicroImagining, Göttingen, Germany) was used to capture the 3D images, which were analyzed by the ZEN 2012 SP1 software (black edition). The technical specifications of the equipment used are as follows: diode laser (405 nm), Ar laser $(458,488,514 \mathrm{~nm})$, diode-pumped solid-state (DPSS) laser $(561 \mathrm{~nm})$ and HeNe laser $(633 \mathrm{~nm})$; AxioObserver Z1 inverted microscope, $63 \times$ apochromatic objective (numerical aperture 1.4); FS49, FS38 and FS15 filters. To capture the autofluorescence of the samples, the emission was measured at a wavelength between 405 and $633 \mathrm{~nm}$. In order to acquire the images, the microparticles were stained with two dyes, DAPI $(1 \mu \mathrm{g} / \mathrm{mL})$ and Red Congo $(40 \mu \mathrm{M})$, in a ratio 3:1:1. The acquisition parameters of the images were as follows: line scan mode, mean method, speed 6, 12-bit depth. In order to increase the signal-to-noise ratio, the frame average of eight scans was used. 


\subsection{Statistical Analysis}

All experimental measurements were performed at least in triplicate, and the results are presented as mean value \pm standard deviation (SD). The one-way analysis of variance (ANOVA) and Tukey's test with a 95\% confidence interval were applied using Minitab 18 software-Free Trial (Ottawa, ON, Canada) to identify significant differences.

\section{Conclusions}

The results obtained in this study emphasize the potential of red beetroot and sour cherry to be used in developing processed foods with no added sugar. This study was focused on evaluating the stability of total phenolics, flavonoids, anthocyanins and betalains of red beetroot and sour cherry in fresh products and marmalades during processing in relation to antioxidant capacity. A significant effect of processing on selected phytochemicals was observed for all samples. When combining red beetroot and sour cherry, a protective effect was evidenced whereby the complex matrix prevented the thermal degradation of phenolic and flavonoids, whereas the anthocyanin concentration was reduced by approximately $50 \%$. Betalains were more heat stable, leading to good preservation of the antioxidant activity. The different thermal behaviors of the bioactives were highlighted by confocal scanning microscopy, showing selected phytochemicals such as betalains and anthocyanins aggregated in clusters of variable sizes, with the cells from the sour cherry marmalade more damaged when compared with those of red beetroot. As expected, red beetroot marmalade showed the highest consistency, with a typical behavior for gels, having a predominantly elastic character.

More studies are needed in order to test the bioavailability of bioactives during digestion and the effect of storage on the preservation of microbial safety in marmalades before the production of these products at an industrial scale. In addition, a sensorial analysis is planned by our research group, in order to test the acceptability of the products.

Author Contributions: Conceptualization, O.V.N. and D.G.A.; methodology, O.V.N. and V.B.; software, D.G.A.; validation, N.S., O.V.N. and G.D.M.; formal analysis, O.V.N. and L.S.; investigation, O.V.N. and D.G.A.; resources, O.V.N. and N.S.; writing-original draft preparation, O.V.N., D.G.A. and V.B.; writing-review and editing, N.S.; visualization, N.S.; project administration, O.V.N.; funding acquisition, N.S. All authors have read and agreed to the published version of the manuscript.

Funding: This research received no external funding.

Acknowledgments: This work was supported by the project "Excellence, performance and competitiveness in the Research, Development and Innovation activities at "Dunarea de Jos" University of Galati", acronym "EXPERT", financed by the Romanian Ministry of Research and Innovation in the framework of Programme 1-Development of the national research and development system, Sub-programme 1.2-Institutional Performance-Projects for financing excellence in Research, Development and Innovation, Contract No. 14PFE/17.10.2018. The authors are grateful for the technical support offered by the Grant POSCCE ID 1815, cod SMIS 48745 (www.moras.ugal.ro). The Integrated Center for Research, Expertise and Technological Transfer in Food Industry is acknowledged for providing technical support.

Conflicts of Interest: The authors declare no conflict of interest.

\section{References}

1. Latorre, M.E.; de Escalada Plá, M.F.; Rojas, A.M.; Gerschenson, L.N. Blanching of red beet (Beta vulgaris L. var. conditiva) root. Effect of hot water or microwave radiation on cell wall characteristics. LWT 2013, 50, 193-203. [CrossRef]

2. Lourenço, E.; Amanda, R.; Teodoro, R.; Henrique, P.; Félix, C.; Victória, R.; Botrel, D.A. Stability of spray-dried beetroot extract using oligosaccharides and whey proteins. Food Chem. 2017, 249, 51-59.

3. Chhikara, N.; Kushwaha, K.; Jaglan, S.; Sharma, P.; Panghal, A. Nutritional, physicochemical, and functional quality of beetroot (Beta vulgaris L.) incorporated Asian noodles. Cereal Chem. 2019, 96, 154-161. [CrossRef]

4. Strack, D.; Vogt, T.; Schlimann, W. Recent advance in betalains research. Phytochemistry 2003, 62, $247-269$. [CrossRef] 
5. Reddy, K.M.; Ruby, L.; Lindo, A.; Nair, G.M. Relative inhibition of lipid peroxidation, cyclooxygenase enzymes and human tumor cells prolifieration by natural food color. J. Agric. Food Chem. 2005, 53, 9268-9273. [CrossRef] [PubMed]

6. Zou, D.; Brewer, M.; Garcia, F.; Feugang, J.M.; Wang, J.; Zang, R. Cactus pear: A natural product in cancer chemoprevention. Nutr. J. 2005, 4, 1-12. [CrossRef] [PubMed]

7. Gentile, C.; Tesoriere, L.; Allegra, M.; Livrea, M.A.; Alessio, P.D. Antioxidant betalains from cactus pear (Opuntia ficus-indica) inhibit endothelial ICAM-1expression. Ann. N. Y. Acad. Sci. 2004, 1028, 481-486. [CrossRef]

8. Preczenhak, A.P.; Tessmer, M.A.; Berno, N.D.; de Abreu Vieira, A.P.; Kluge, R.A. Initial stages of minimal processing of red beets result in significant loss of bioactive compounds. LWT 2018, 96, 439-445. [CrossRef]

9. Guiné, R.P.F.; Roque, A.R.F.; Gonçalves, F.J.A.; Correia, P.M.R. Development of an innovative jam based on beetroot. J. Food Res. 2016, 1, 49-53.

10. de Oliveira, V.S.; Ferreira, F.S.; Cople, M.C.R.; Labre, T.D.S.; Augusta, I.M.; Gamallo, O.D.; Saldanha, T. Use of Natural Antioxidants in the Inhibition of Cholesterol Oxidation: A Review. Compr. Rev. Food Sci. Food Saf. 2018, 17, 1465-1483. [CrossRef]

11. Tian, Y.; Puganen, A.; Alakomi, H.L.; Uusitupa, A.; Saarela, M.; Yang, B. Antioxidative and antibacterial activities of aqueous ethanol extracts of berries, leaves, and branches of berry plants. Food Res. Int. 2018, 106, 291-303. [CrossRef] [PubMed]

12. Khan, M.I. Plant Betalains: Safety, Antioxidant Activity, Clinical Efficacy, and Bioavailability. Compr. Rev. Food Sci. Food Saf. 2016, 15, 316-330. [CrossRef]

13. Panghal, A.; Virkar, K.; Kumar, V.B.; Dhull, S.; Gat, Y.; Chhikara, N. Development of probiotic beetroot drink. Curr. Res. Nutr. Food Sci. J. 2017, 5, 257-262. [CrossRef]

14. Güneşer, O. Pigment and Colour Stability of Beetroot Betalains in Cow Milk during Thermal Treatment. Food Chem. 2016, 196, 220-227. [CrossRef]

15. Ferretti, G.; Bacchetti, T.; Belleggia, A.; Neri, D. Cherry antioxidants: From farm to table. Molecules 2010, 15, 6993-7005. [CrossRef] [PubMed]

16. Kirakosyan, A.; Seymour, E.M.; Urcuyo Llanes, D.E.; Bolling, S.F. Chemical profile and antioxidant capacities of tart cherry products. Food Chem. 2009, 115, 20-25. [CrossRef]

17. Özen, M.; Özdemir, N.; Ertekin Filiz, B.; Budak, N.H.; Kök-Taş, T. Sour Cherry (Prunus cerasus L.) Vinegars Produced from Fresh Fruit or Juice Concentrate: Bioactive Compounds, Volatile Aroma Compounds and Antioxidant Capacities. Food Chem. 2020, 309, 125664. [CrossRef] [PubMed]

18. Castellanos-Santiago, E.; Yahia, E.M. Identification and Quantification of Betalains from the Fruits of 10 Mexican Prickly Pear Cultivars by High-Performance Liquid Chromatography and Electrospray Ionization Mass Spectrometry. J. Agric. Food Chem. 2008, 56, 5758-5764. [CrossRef]

19. Desseva, I.; Stoyanova, M.; Petkova, N.; Mihaylova, D. Red Beetroot Juice Phytochemicals Bioaccessibility: An Approach. Pol. J. Food Nutr. Sci. 2020, 70, 45-53. [CrossRef]

20. Guldiken, B.; Toydemir, G.; Memis, K.N.; Okur, S.; Boyacioglu, D.; Capanoglu, E. Home-Processed Red Beetroot (Beta vulgaris L.) Products: Changes in Antioxidant Properties and Bioaccessibility. Int. J. Mol. Sci. 2016, 17, 858. [CrossRef]

21. Ravichandran, K.; Thaw Saw, N.M.M.; Mohdaly, A.A.A.; Gabr, A.M.M.; Kastell, A.; Riedel, H.; Cai, Z.; Knorr, D.; Smetanska, I. Impact of processing of red beet on betalain content and antioxidant activity. Food Res. Int. 2013, 50, 670-675. [CrossRef]

22. Han, B.; Bhagavathula, A.S.; Rashid, M.; Chhabra, M.; Clark, C.; Abdulazeem, H.M.; Abd-ElGawad, M.; Varkaneh, H.K.; Rahmani, J.; Yong Zhang, Y. The effect of sour cherry consumption on blood pressure, IL-6, CRP, and TNF-a levels: A systematic review and meta-analysis of randomized controlled trials sour cherry consumption and blood pressure. J. King Saud Univ. Sci. 2020, 32, 1687-1693. [CrossRef]

23. Yılmaz, F.M.; Görgüç, A.; Karaaslan, M.; Vardin, H.; Bilek, S.E.; Uygun, Ö.; Bircan, C. Sour Cherry By-products: Compositions, Functional Properties and Recovery Potentials-A Review. Crit. Rev. Food Sci. Nutr. 2018, 59, 3549-3563. [CrossRef]

24. Igual, M.; Contreras, C.; Martínez-Navarrete, N. Colour and rheological properties of non-conventional grapefruit jams: Instrumental and sensory measurement. LWT 2014, 56, 200-206. [CrossRef] 
25. Rababah, T.M.; Al-U’Datt, M.; Al-Mahasneh, M.; Yang, W.; Feng, H.; Ereifej, K.; Kilani, I.; Ishmais, M.A. Effect of jam processing and storage on phytochemicals and physiochemical properties of cherry at different temperatures. J. Food Process. Preserv. 2014, 38, 247-254. [CrossRef]

26. Igual, M.; Contreras, C.; Martínez-Navarrete, N. Non-conventional techniques to obtain grapefruit jam. Innov. Food Sci. Emerg. Technol. 2010, 11, 335-341. [CrossRef]

27. Barbieri, S.F.; de Oliveira Petkowicz, C.L.; Bueno de Godoy, R.C.; de Azeredo, H.C.M.; Cavichiolo Francod, C.R.; Silveira, J.L.M. Pulp and Jam of Gabiroba (Campomanesia xanthocarpa Berg): Characterization and Rheological Properties. Food Chem. 2018, 263, 292-299. [CrossRef]

28. Basu, S.; Shivhare, U.S.; Singh, T.V.; Beniwal, V.S. Rheological, textural and spectral characteristics of sorbitol substituted mango jam. J. Food Eng. 2011, 105, 503-512. [CrossRef]

29. Gabriele, D.; De Cindio, B.; D'Antona, P. A weak gel model for foods. Rheol. Acta 2001, 40, 120-127. [CrossRef]

30. Figueroa, L.E.; Genovese, D.B. Fruit jellies enriched with dietary fibre: Development and characterization of a novel functional food product. LWT 2019, 111, 423-428. [CrossRef]

31. Banas, A.; Korus, A.; Korus, J. Texture, Color, and Sensory Features of Low-Sugar Gooseberry Jams Enriched with Plant Ingredients with prohealth properties. J. Food Qual. 2018, 1646894, 1-12. [CrossRef]

32. Garrido, J.I.; Lozano, J.E.; Genovese, D.B. Effect of formulation variables on rheology, texture, colour, and acceptability of apple jelly: Modelling and optimization. LWT 2015, 62, 325-332. [CrossRef]

33. Miguel, M.C. Betalains in Some Species of the Amaranthaceae Family: A Review. Antioxidants 2018, 7, 53. [CrossRef]

34. Cabrera-Bañegil, M.; del Hurtado-Sánchez, M.C.; Galeano-Díaz, T.; Durán-Merás, I. Front-face fluorescence spectroscopy combined with second-order multivariate algorithms for the quantification of polyphenols in red wine samples. Food Chem. 2017, 220, 168-176. [CrossRef]

35. Stintzing, F.C.; Schieber, A.; Carle, R. Evaluation of colour properties andchemical quality parameters of cactus juices. Eur. Food Res. Technol. 2003, 216, 303-311. [CrossRef]

36. Tõnutare, T.; Moor, U.; Wojciech Szajdak, L. Strawberry anthocyanin determination by $\mathrm{pH}$ differential spectroscopic method-How to get true results? Acta Sci. Pol. Hortorum Cultus 2014, 13, 35-47.

37. Giusti, M.M.; Wrolstad, R.E. Anthocyanins. Characterization and measurement with UV-visible spectroscopy. In Current Protocols in Food Analytical Chemistry Wrolstad; Wrolstad, R.E., Ed.; Wiley: New York, NY, USA, 2001; pp. F1.2.1-F1.2.13.

38. Singleton, V.L.; Orthofor, R.; Raventos, R.M.L. Analysis of total phenols and other oxidation substrates and antioxidants by means of Folin-Ciocaltau reagent. Methods Enzymol. 1999, 299, 152-178.

39. Marinova, D.; Ribarova, F.; Atanassova, M. Total phenolic and total flavonoids in Bulgarian fruits and vegetables. J. Univ. Chem. Technol. Metall. 2005, 40, 255-260.

Sample Availability: Samples of the compounds are not available from the authors.

Publisher's Note: MDPI stays neutral with regard to jurisdictional claims in published maps and institutional affiliations.

(C) 2020 by the authors. Licensee MDPI, Basel, Switzerland. This article is an open access article distributed under the terms and conditions of the Creative Commons Attribution (CC BY) license (http://creativecommons.org/licenses/by/4.0/). 